\title{
Analisa Kerjasama Pihak Corporate dengan Masyarakat dalam Pengembangan Pariwisata di Desa Singapadu Kaler, Kabupaten Gianyar
}

Claudia Grace Kusumawardani a, 1, Putri Kusuma Sanjiwani a, 2

${ }^{1}$ claudiagrace1998@gmail.com ,2 kusumasanjiwani@unud.ac.id

a Program Studi S1 Destinasi Pariwisata, Fakultas Pariwisata,Universitas Udayana, Jl. Dr. R. Goris, Denpasar, Bali 80232 Indonesia

\begin{abstract}
In village tourism developing, it is necessary to have cooperation carried out by tourism Stakeholders, both Government, Community and Entrepreneurs or private parties. The collaboration must be balanced according to the status and role of each stakeholder so that harmonious cooperation can be created that is impartial to anyone. The research method used is a qualitative method with qualitative data analysis techniques, The source of data from this study comes from primary and secondary data. Data collection techniques are carried out by observation, in-depth interviews and documentation. Determination of informants is done by purposive sampling procedure. The results of this study indicate that based on the characteristics, tasks, objectives and functions of the BUMDES ( Badan Usaha Milik Desa ) are still not optimal, it can be seen that a number of things that have not yet fulfilled and still need to be reviewed so that BUMDES ( Badan Usaha Milik Desa) can collaborate and coordinate tourism village units optimally.
\end{abstract}

Keywords: Corporate, Community, Tourism Development

\section{PENDAHULUAN}

Sebagai daerah tujuan wisata Bali memiliki banyak daya tarik wisata menarik untuk dikunjungi baik itu daya tarik wisata budaya, alam dan buatan. Perkembangan kepariwisataan di Bali kini telah mengalami kemajuan yang pesat,baik dari segi kuantitas maupun kualitas. Bali juga merupakan daerah yang menjadi sasaran investor karena memiliki nilai jual (Hariyana dan Mahagangga, 2015). Bali mempunyai delapan kabupaten yang memiliki keunikan pada alam maupun budayanya seperti salah satunya yaitu Kabupaten Gianyar. Kabupaten Gianyar mempunyai 64 desa dan saat ini sedang melakukan membangun desa - desa untuk dijadikan sebagai desa wisata yang nantinya memanfaatkan Sumber Daya Alam, Sumber Daya Manusia serta Sumber Daya Buatan yang dipunya. Salah satu desa yang baru saja dicanangkan sebagai Desa Wisata ialah Desa Wisata Singapadu Kaler.

Desa Singapadu Kaler dicanangkan menjadi desa wisata pada tahun 2018. Desa Wisata Singapadu Kaler ini merupakan wujud pemerataan pariwisata sebagai upaya peningkatan kesejahteraan untuk masyarakat oleh Pemerintah Kabupaten Gianyar. Dengan dijadikan sebagai desa wisata tentu pengembangan desa wisata sangatlah penting karena sebagai pelestari seni dan budaya serta pariwasata kerakyatan, masyarakat juga turut langsung menjadi pelaku sekaligus mendapat pendapatan dari pariwisata. Selain itu, lokasi Desa Wisata Singapadu Kaler pun didukung karena merupakan jalur pariwisata yang sering dilewati oleh wisatawan. Masyarakat Desa Singapadu Kaler terus melakukan upaya pengembangan agar desa semakin maju dan terkenal. Dalam hal pengembangan di Desa Singapadu Kaler, terdapat sebuah kerjasama seperti pemenuhan fasilitas ATV untuk atraksi yang terhimpun dalam satu kesatuan atau yang disebut dengan Corporate. Corporate yang dimaksud ialah sekelompok orang atau masyarakat banjar yang memiliki fasilitas yang sama dan dapat dipinjamkan untuk menambah fasilitas yang ada saat wisatawan yang berkunjung overload. Corporate yang ada merupakan sekelompok masyarakat namun masih berkelompok sendiri- sendiri, maka dari itu masyarakat desa yang diwakili oleh BUMDES (Badan Usaha Milik Desa) ingin menghimpun corporate - corporate tersebut ke dalam naungan BUMDES (Badan Usaha Milik Desa) agar lebih terorganisir dan meminimalisir terjadinya persaingan antar jasa usaha hiburan serta corporate - corporate tersebut juga mendapatkan kemudahan dalam hal perpajakan atau pelindungan.Fokus penelitian dalam artikel ini adalah kondisi eksisting di Desa Wisata Singapadu Kaler, Kabupaten Gianyar. dan kerjasama pihak corporate dengan masyarakat dalam pengembangan pariwisata di desa Singapadu Kaler, Kabupaten Gianyar. Adapun lingkup permasalahan dalam penelitian ini yaitu kondisi eksisting berdasar komponen $4 a$ (Cooper dalam Suryawan dan Mahagangga, 2017) dan perubahan utama desa menjadi desa wisata serta kerjasama pihak corporate dengan masyarakat berdasar ciri, tugas tujuan, dan fungsi BUMDES (Badan Usaha 
Milik Desa) serta analisa kerjasama antara pihak corporate dengan masyarakat. Dalam penelitian ini, menggunakan beberapa konsep dan teori, seperti teori perikatan, konsep pariwisata, dan konsep daya tarik wisata. Selain itu, terdapat tinjauan pustaka atau telaah hasil penelitian sebelumnya yang sangat penting untuk dijadikan sebagai acuan peneliti. Penelitian sebelumnya yang pertama oleh Salahudin Salviana tentang Model kerjasama antar Stakeholders dalam pengembangan wisata budaya Dusun Sejo dengan tujuan dan hasil penelitian mengenai model kerjasama antar Stakeholder dalam pengembangan wisata budaya di Dusun Sejo. Hasil yang meliputi : 1). Bentuk keterlibatan antar Stakeholder dalam pengembangan 2). Model kerjasama yang digunakan ialah Collaborative governance, 3). Masih terdapat beberapa kendala yang dihadapi dalam pengembangannya. Selanjutnya penelitian oleh Suarditya dan Sunarta ( jurnal Destinasi Pariwisata ) Vol. 5, No. 1, 2017 tentang Strategi pengembangan Banjar Samu, Singapadu Kaler sebagai desa wisata di Kecamatan Sukawati, Kabupaten Gianyar dengan tujuan dan hasil penelitian yang meliputi: 1). Potensi wisata yang ada di Banjar Samu terdiri dari potensi Alam dan potensi Budaya, 2). Analisis Strategi memakai SWOT. Di dalam Penelitian ini mengkaji bagaimana SWOT ( peluang, hambatan, kekuatan dan kelemahan ) saling dipadu padankan sehingga dapat menjadi pengetahuan dan mencegah hal buruk terjadi.

\section{METODE PENELITIAN}

Berdasarkan jenisnya, data yang digunakan dalam penelitian ini adalah data kuantitatif dan data kualitatif (Bungin, 2007; Kusumayadi dan Sugiarto, 2000). Sumber data yang digunakan dalam penelitian ini adalah data primer dan data sekunder (Moleong, 2006). Teknik pengumpulan data yang digunakan dalam penelitian ini diantaranya observasi (Suryawan dan Mahagangga, 2017), wawancara (Moleong, 2006) dan dokumentasi (Moleong, 2012). Teknik analisis data yang digunakan dalam penelitian ini diantaranya adalah analisis data kualitatif menurut Bogdan dan Biklen dalam Moleong (2012), bahwa analisis data kualitatif merupakan upaya yang dilakukan dengan jalan bekerja dengan data, mengorganisasikan data, memilah-milahnya menjadi satuan yang dapat dikelola, mencari dan menemukan pola, menemukan apa yang penting, apa yang dipelajari, dan memutuskan apa yang dapat diceritakan kepada orang lain.

\section{HASIL DAN PEMBAHASAN}

Desa Singapadu Kaler merupakan sebuah desa yang secara administratif berada di Kecamatan
Sukawati, Kabupaten Gianyar. Desa Singapadu Kaler terdiri dari lima banjar, yaitu:

1. Banjar Dinas Samu,

2. Banjar Dinas Silakarang,

3. Banjar Dinas Kederi,

4. Banjar Dinas Belang Samu,

5. Banjar Dinas Belang Kaler.

\subsection{Kondisi Eksisting di Desa Singapadu Kaler}

a. Attraction (daya tarik)

Desa Singapadu Kaler merupakan desa yang terkenal daya tarik buatannya yaitu desa wisata berupa ATV. ATV menjadi andalan Desa Singapadu Kaler karna suasana alam di desa yang sangat mendukung seperti masih banyak hamparan sawah serta terdapat trek khusus untuk bermain ATV. Trek yang dilewati oleh ATV selain persawahan juga mengelilingi Desa Singapadu Kaler sehingga wisatawan juga tidak hanya sekedar untuk bermain ATV namun dapat merasakan kehidupan desa secara tidak langsung.

Selain mempunyai atraksi utama berupa desa wisata yaitu $A T V$, desa Singapadu Kaler juga memiliki atraksi lainnya sebagai atraksi pendukung, seperti:

1. Atraksi Hiburan lainnya

Meliputi Flying Fox, Sepeda Terbang, Swing atau ayunan dan tubing atau perahu karet. Umumnya. Permainan Flying fox, sepeda terbang dan ayunan berada dalam satu kawasan atau satu tempat dengan ATV, sehingga wisatawan dapat membeli paket secara bersamaan.

2. Tarian Tradisional

Contoh tarian tradisionalnya yaitu tarian Arja, yaitu sebuah kesenian berupa tarian yang sudah ada sejak 1960 dan dilestarikan agar tidak terlupakan.

3. Yoga \& Spa Bali

Yoga dan meditasi ala Bali dapat ditemui di Griya Tauman dimana kegiatan komunitas yoga-meditasi sudah berlangsung puluhan tahun.

4. Tradisi "Nguber Bebek"

Nguber bebek atau menangkap itik merupakan salah satu tradisi yang unik yang ada di salah satu Banjar yang ada, yaitu Banjar Samu.

5. Pura \& Mata Air 
Terdapat 3 Pura yang ada di Desa Singapadu Kaler ini,yaitu Pura Beji Ngiyangan, Pura Puncak Sari dan Pura Taman Sari. Serta terdapat mata Air yang juga sering dijadikan sebagai tempat melukat.

6. Pohon Lubang

Terdapat sebuah Pohon dengan bentuk yang unik yakni dibatang terdapat lubang yang dapat dijadikan spot foto oleh wisatawan untuk berfoto Selfie.

Selain itu, juga terdapat beberapa potensi yang nantinya juga akan menjadi daya tarik wisata di Desa Singpadu Kaler, seperti :

1. Trekking Persawahan

Trekking Persawahan merupakan sebuah atraksi yang baru yang berpusat di Banjar Samu dimana jalur trekkingnya berada dipinggir sawah sepanjang desa Singapadu Kaler.

2. Subak

Terdapat sebuah Subak, yaitu Subak Wahem yang sudah d ikunjungi oleh wisatawan.

3. Patung

Patung merupakan salah satu handmade yang dibuat oleh masyarakat desa Singapadu Kaler. Patung - patung disini juga akan dijadikan sebagai brand dari desa Singapadu Kaler. Brand yang akan diusung ialah Desa 1000 Patung.

b. Accesability ( aksesbilitas )

Untuk mencapai Desa Wisata Singapadu Kaler dapat menggunakan beberapa transportasi, seperti motor atau mobil pribadi, transportasi umum seperti taxi atau bus. Sedangkan untuk Jalan Raya yang ada di Desa Singapadu Kaler sudah memadai, tidak ada jalan yang rusak parah.

c. Amenities ( fasilitas )

Desa Singapadu Kaler mempunyai beberapa fasilitas yang tesedia seperti :

1. Restoran

Contoh restoran yang ada yaitu Restoran Tepi Tebing. Restoran ini memiliki pemandangan taman dan kolam yang dipinggirnya diberi gazebo untuk bersantai sambil menikmati hidangan.

2. Penginapan

Untuk hal penginapan, di Desa

Singpadu Kaler sudah tersedia 2 jenis penginapan yaitu:

a. HomeStay
Singapadu Kaler sudah memiliki beberapa homestay yang dapat disewakan. Harganya pun bervariatif dari Rp 160.000 hingga Rp 600.000. Jumlah homestay yang tersedia saat ini sudah ada 3 unit.

b. Villa

Salah satu Villa yang sudah terkenal yaitu Uma Luwih Villa. Dimana Villa ini sudah terkenal dan pemesanannya pun cukup mudah karena sudah ada di aplikasi smartphone. Harganya sekitar Rp 400.000 hingga Rp 2.500.000. Jumlah villa yang sudah ada sebanyak 7 unit.

3. Lahan Parkir

Lahan Parkir yang tersedia saat ini cukup untuk menampung kendaraan wisatawan. Tata letak lahan parkir tergolong rapi karena belum ada kendaraan wisatawan yang mengambil bahu jalan untuk dijadikan area parkir kendaraan.

4. Pom Bensin

Tersedia pom bensin untuk wisatawan yang membawa kendaraan.

5. Fasilitas Kesehatan

Untuk fasilitas kesehatan sudah memadai, seperti puskesmas, apotik, toko obat, rumah/ praktek dokter. Untuk kebersihan, Desa Singapadu Kaler memiliki tempat sampah sebanyak 20 unit yang tersebar di lingkungan Desa.

\section{d. Ancillary ( kelembagaan )}

Berikut merupakan komposisi Stakeholder di Desa Singapadu Kaler :

Tabel 1. Komposisi Stakeholder di Desa Singapadu Kaler

\begin{tabular}{|l|l|l|}
\hline PEMERINTAH & \multicolumn{1}{|c|}{$\begin{array}{c}\text { PENGUSAHA } \\
\text { SWASTA }\end{array}$} & $\begin{array}{c}\text { MASYARAKAT } \\
\text { LOKAL }\end{array}$ \\
\hline 1. Desa Dinas & $\begin{array}{l}\text { 1. BUMDES ( } \\
\text { Badan Usaha } \\
\text { Milik Desa })\end{array}$ & 1. PKK \\
2.Pokdarwis \\
\hline
\end{tabular}


Vol. 8 No 1, 2020

\begin{tabular}{|l|l|l|}
\hline PEMERINTAH & \multicolumn{1}{|c|}{$\begin{array}{c}\text { PENGUSAHA } \\
\text { SWASTA }\end{array}$} & \multicolumn{1}{c|}{ LASYARAKAT } \\
\hline 2. Dinas & 2.Corporate Desa & 3. Karang taruna \\
Pariwisata & Wisata (ATV) & 4.Kelompok Tani \\
Kabupaten & & Nelayan \\
Gianyar & & 5.Organisasi \\
3. Dinas & & Perempuan \\
Sosial & & Organisasi \\
Kabupaten & & \\
Gianyar & & \\
4. Kebesihan & & \\
dan & & \\
Pertamanan & & \\
( DKP) & & \\
LPMK & &
\end{tabular}

Sumber : Hasil Penelitian. 2019

Dalam Kelembagaan Pemerintah, Desa Singapadu Kaler merupakan sebuah Desa Dinas yang dibantu oleh Dinas Pariwisata sebagai pembimbing dan Dinas Sosial Kabupaten Gianyar. Dengan adanya dua Dinas yang membantu ini agar Desa Singapadu Kaler dapat mengetahui bagaimana proses pengembangan desa karena desa Singapadu kaler merupakan salah satu Desa Wisata baru di Kabupaten Gianyar dan Desa Singapadu Kaler dapat membuat program - program baru terkait potensi yang dipunya dan program tersebut dibimbing dan didukung oleh Dinas Pariwisata maupun Dinas Sosial Kabupaten Gianyar. Selain itu juga, di Desa Singapadu Kaler juga sudah ada kelompok masyarakat yang mempunyai tugas masing- masing sehingga dapat dikatakan bahwa masyarakat desa sudah aktif berpartisipasi.

\section{e.Perubahan Utama Sebuah Desa menjadi Desa Wisata}

Setelah menjadi Desa Wisata Singapadu Kaler, terdapat beberapa perubahan, seperti :

\section{a. Lingkungan}

Kondisi lingkungan yang lebih bersih karena seperti contoh Banjar Samu yang melakukan kegiatan gotong royong dalam 1 - 2 minggu sekali untuk membersihkan lingkungan dan menjaga kebersihan.

b. Ekonomi

Perubahan yang terjadi lainnya yaitu angka pengangguran pun menurun khususnya orang muda karena semenjak dijadikan Desa Wisata, banyak terdapat lapangan pekerjaan yang baru sehingga orang muda dapat diberdayakan untuk bekerja dan tidak lesu seperti dulu yang tidak mempunyai pekerjaan.

c. Sosial

Dengan adanya kegiatan gotong royong dan sudah dijadikan desa wisata, membuat kehidupan sosial dalam masyarakat pun semakin dekat untuk saling bersatu padu untuk menjaga Desa agar tetap aman dan nyaman untuk masyarakat sendiri ataupun wisatawan.

\subsection{Kerjasama Pihak Corporate dengan masyarakat}

Dalam hal pengembangan pariwisata, di desa Singapadu Kaler terdapat sebuah kerjasama antara pihak corporate dengan masyarakat desa dengan tujuan untuk lebih mengembangkan pariwisata yang ada di Desa Singapadu Kaler. Pihak Corporate yang dimaksud ialah sekelompok masyarakat yang mempunyai jenis usaha yang sama namun berdiri sendiri- sendiri maksudnya ialah belum ada organisasi yang menghimpun atau mengelola. Dimana sekelompok masyarakat tersebut mempunyai jenis usaha wisata hiburan berupa ATV. Sudah banyak bahkan hampir sebagian besar masyarakat desa Singapadu Kaler bekerja dalam bidang usaha desa wisata berupa ATV. Dengan melihat banyaknya kelompok masyarakat yang memiliki usaha desa wisata ini, maka dari itu masyarakat desa yang diwakili oleh BUMDES ( Badan Usaha Milik Desa ) menawarkan kerjasama dengan pihak corporate atau pihak usaha unit desa wisata agar terciptanya sinegritas kerjasama antar stakeholder dalam pengembangan pariwisata di Desa Singapadu Kaler secara bersama.

Saat ini, kelompok masyarakat yang menjadi pihak corporate sudah ada 7 unit atau 7 kelompok dan 1 unit lagi sedang merintis usaha. Penghasilan dari bekerja sebagai usaha desa wisata berbentuk usaha atv ini sangat besar nilainya. Pencapaiannya dalam sebulan rata - rata sebesar Rp. 200.000.000 hingga 300.000.000 juta/ bulan.

Walaupun mendapatkan pendapatan yang banyak, namun masyarakat yang menjadi pihak corporate merasa ingin mendapatkan dukungan yang lebih dari pihak desa dan juga ingin melakukan kerjasama dan sebaliknya, maka pihak desa pun juga menginginkan adanya upaya kerjasama dengan para masyarakat agar terjadinya sebuah kesepakatan yang saling menguntungkan. 


\section{a.Tugas, Tujuan dan Fungsi BUMDES}

Menurut Undang - Undang Nomor 6 tahun 2014 tentang Desa Pasal 1 ayat 6 , menyatakan bahwa Badan Usaha Milik Desa, yang selanjutnya disebut BUMDES, adalah badan usaha yang seluruh atau sebagian besar modalnya dimiliki oleh Desa melalui penyertaan secara langsung yang berasal dari kekayaan Desa yang dipisahkan guna mengelola aset, jasa pelayanan, dan usaha lainnya untuk sebesar kesejahteraan masyarakat Desa.

Adapun ciri-ciri dari BUMDES, antara lain:

1. Kekuasaan penuh di tangan desa, dan dikelola bersama masyarakat desa.

2. Modal bersama yakni bersumber dari desa sebesar 51\% dan dari masyarakat 49\%, dilakukan dengan cara penyerataan modal (saham atau andil).

3. Menggunakan falsafah bisnis yang berakar dari budaya lokal untuk melakukan kegiatan operasional. Proses operasionalisasi ini di kontrol bersama oleh BPD,Pemerintah Desa dan anggota masyarakat.

4. Untuk bidang yang dipilih bagi badan usaha desa disesuaikan dengan potensi dan informasi pasar.

5. Keuntungan yang diperoleh dari produksi dan penjualan ditujukan untuk meningkatkan kesejahteraan anggota dan masyarakat desa melalui kebijkan desa.

6. Pemberian fasilitas dan pengawasan dilakukan oleh Pemerintah Provinsi, Pemerintah Kabupaten, dan Pemrintah Daerah.

Berikut ini adalah tugas, tujuan dan fungsi BUMDES

Tabel 2 Tugas, Tujuan dan Fungsi BUMDES

\begin{tabular}{|l|l|l|}
\hline \multicolumn{1}{|c|}{ Tugas } & \multicolumn{1}{|c|}{ Tujuan } & \multicolumn{1}{c|}{ Fungsi } \\
\hline 1.Menciptakan & 1.Meningkatkan & 1.Sebagai \\
kesejahteraan & kesejahteraan & Lembaga Sosial \\
warga dengan & masyarakat & \\
memanfaatkan & desa melalui & 2.Sebagai \\
aset dan & pengelolaan & Lembaga \\
potensi yang & potensi desa & Komersial \\
dimiliki desa & sesuai dengan & \\
& kebutuhan & \\
& masyarakat & \\
\hline
\end{tabular}

\begin{tabular}{|c|c|c|}
\hline Tugas & Tujuan & Fungsi \\
\hline $\begin{array}{l}\text { 2.Memberikan } \\
\text { modal penyertaan } \\
\text { dari desa terhadap } \\
\text { unit usaha yang } \\
\text { ada di desa }\end{array}$ & $\begin{array}{l}\text { desa } \\
\text { 2.Meningkatkan } \\
\text { perekonomian dan } \\
\text { pendapatan } \\
\text { masyarakat } \\
\text { 3.Mengoptimalkan } \\
\text { potensi SDA untuk } \\
\text { kebutuhan masyarakat } \\
\text { 4.Menjadi alat } \\
\text { pemerata dan } \\
\text { pertumbuhan ekonomi } \\
\text { desa }\end{array}$ & \\
\hline
\end{tabular}

Sumber: Hasil Penelitian, 2019

Selain itu, juga terdapat beberapa jenis usaha yang ada dalam BUMDES. Salah satunya ialah Usaha Bersama/Holding. Yang dimaksud dengan Usaha Bersama atau Holding yaitu BUMDES membangun sistem usaha terpadu yang melihatkan banyak usaha di desa. Misalnya, BUMDes mengelola wisata desa dan membuka akses seluasnya pada penduduk untuk bisa mengambil berbagai peran yang dibutuhkan dalam kegiatan usaha wisata itu.

\section{b. Analisa kerjasama pihak corporate dengan masyarakat dalam pengembangan pariwisata di Desa Singapadu Kaler}

Adapun isi dari kerjasama dari pihak corporate dengan pihak desa melalui BUMDES, yaitu:

1. Membentuk Holding Company dengan masing - masing pihak mengeluarkan modal Rp 500.000.000.

Maksudnya ialah, 7 unit corporate atau 7 kelompok masyarakat dan BUMDES sama - sama mengeluarkan modal sebesar Rp 500.000 .000 untuk membentuk Holding Company guna awal bentuk kerjasama ke dua belah pihak dan adapun bentuk modal tersebut dalam bentuk kendaraan ATV.

2. Perpajakan

Dalam hal urusan perpajakan, jika kerjasama ini sudah terbentuk, maka dalam hal perpajakan akan ditangani oleh BUMDES namun biaya untuk membayar pajak tetap dibayarkan oleh masing- masing pihak corporate atau 
unit desa wisata sesuai pendapatan mereka.

3. Perlindungan

Dalam hal perlindungan, 7 Unit desa wisata akan mendapatkan perlindungan secara lingkungan. Maksudnya ialah apabila terdapat sebuah masalah yang menyangkut mengenai unit desa wisata, maka BUMDES akan turut membantu sebagai pihak mediator atau mediasi.

4. Iuran wajib

Selain itu, setiap unit desa wisata akan dikenai iuran wajib sebesar $\mathrm{Rp}$ 150.000/ hari dan iuran Rp 500.000/ bulan dimana iuran ini dipergunakan untuk sumbangan kegiatan agama yang ada di Desa.

5. Operasional

Dalam hal Operasional seperti Gaji para karyawan dari unit desa wisata sepenuhnya merupakan tanggung jawab atau urusan dari masing - masing unit desa wisata dan bukan urusan dari pihak BUMDES karena pendapatan dari setiap unit berbeda - beda.

6. Modal 2tahun

Selain itu, pihak BUMDES dan unit desa wisata juga bekerjasama dalam hal permodalan. BUMDES memberikan modal dengan masing - masing unit desa wisata sebesar Rp 70.000.000 dengan kontrak selama dua tahun dengan ketentuan membayar $\mathrm{Rp}$ $150.000 /$ hari.

7. Sanksi

Didalam kerjasama ini, terdapat peraturan jika salah satu pihak melanggar akan dikenakan sanksi. Sanksi yang diberikan berupa peringatan di awal dan berupa musyawarah.

Dengan melihat isi dari kerjasama dari pihak corporate dengan masyarakat melalui BUMDES, maka analisa kerjasama yang terjalin :

1. Analisa yang belum sesuai :

a. Tujuan BUMDES

1. Salah satu tujuan dibentuknya BUMDES ( Badan Usaha Milik Desa) adalah sebagai alat pemerataan dan pertumbuhan ekonomi desa. Di dalam isi kerjasama belum tercantum BUMDES sebagai pemerata dan pertumbuhan ekonomi desa. Hal yang seharusnya dapat dilakukan BUMDES dalam melakukan pemerataan dan pertumbuhan ekonomi desa, seperti BUMDES berperan sebagai koordinator yang membantu dalam meratakan jumlah wisatawan yang datang ke setiap unit desa wisata yang secara tidak langsung berdampak pada perekonomian desa.

2. Dalam hal Pemerataan, BUMDES juga dapat mendirikan Badan Pengelola sebagai Manajemen Operasional yang bertugas untuk menjamin Pemerataan sehingga dalam hal Operasional yaitu Gaji Karyawan dapat disalurkan secara merata agar kesejahteraan masyarakatpun terjamin.

3. Dengan melihat salah satu ciri dari Bumdes yaitu adanya modal bersama dari pihak desa ( BUMDES ) sebanyak $51 \%$ dan masyarkat sebanyak 49\%, maka hal ini jika ditinjau dari isi kerjasama yang menyatakan BUMDES dengan unit desa wisata memberikan modal dengan nominal yang sama, maka kurang sesuai kerjasama dalam hal modal. Seharusnya modal yang dikeluarkan oleh desa melalui pihak BUMDES lebih besar disbanding unit desa wisata.

4. Penambahan Point Kerjasama

Setiap unit desa wisata, memiliki jalur khusus ( trekking ) ATV sesuai lahan yang dipunya sehingga trekking unit desa wisata tidak ada yang sama. Hal ini tentu menimbulkan adanya perbedaan. Maka dapat ditambahkan dalam isi kerjasama, BUMDES dapat berperan dalam mengatur dan mengajak seluruh unit desa untuk mengelola jalur atau trekking ATV sehingga semua unit desa wisata mendapatkan manfaat yang sama.

2. Analisa yang sudah sesuai

a. Tugas BUMDES

Tugas BUMDES ada 2, yaitu menciptakan kesejahteraan warga dengan memanfaatkan aset dan potensi yang dimiliki desa dan memberikan modal penyertaan dari desa terhadap unit usaha yang ada di desa.

1. Dalam hal menciptakan kesejahteraan warga dengan memanfaatkan aset dan potensi yang dimiliki desa sudah berjalan. Dilihat dari kebebasan yang diberikan BUMDES untuk masyarakat dalam memanfaatkan aset dan potensi desa seperti para masyarakat sebagai unit desa wisata atau para pengusaha ATV 
untuk melakukan usaha. Semua unit desa wisata diberikan kebebasan dalam memanfaatkan Alam desa sebagai jalur atau trek untuk bermain ATV tentu dalam pelaksanaannya tetap diawasi agar tidak merusak alam.

2. Selain itu, dalam pemberian modal dari desa melalui BUMDES juga sudah terlaksana, terlihat dari adanya kesepakatan dalam pembangunan Holding Company dengan Bumdes dan para unit desa wisata membayar modal sebesar Rp 50.000.000 dan juga peminjaman modal dari BUMDES terhadap setiap unit desa wisata sebesar Rp 70.000.000 dan dapat dibayarkan oleh setiap unit desa Rp 150.000/hari.

b. Tujuan BUMDES

1. Dalam meningkatkan kesejahteraan masyarakat desa melalui pengelolaan potensi desa sesuai dengan kebutuhan masyarakat sudah berjalan dengan sesuai. Hal ini dapat kita lihat dari adanya pengelolaan awal terhadap potensi - potensi yang ada semisal potensi handmade patung yang mau ditambahkan dalam permainan ATV dan tentu akan berdampak pada bertambahnya kebutuhan masyarakat dalam hal pendapatan secara tidak langsung. Dan mengoptimalkan potensi SDA untuk kebutuhan masyarakat, pihak Desa sudah berusaha mengoptimalkan potensi yang ada seperti akan ada jalur trek di sekitar persawahan untuk berjalan santai.

c. Fungsi BUMDES

Dalam menjalankan fungsi sebagai BUMDES,maka :

1. Sebagai Lembaga Sosial

BUMDES sebagai Lembaga Sosial tentu harus berpihak kepada kepentingan masyarakat melalui kontribusinya dalam penyediaan pelayanan sosial. Dalam hal ini, di Desa Singapadu Kaler sudah ada lembaga - lembaga pelayanan sosial, seperti lembaga keluarga, lembaga adat, lembaga kemasyarakatan. Selain itu juga, BUMDES sudah berperan membantu kepentingan masyarakat melalui kontribusinya berupa memberikan Perlindungan secara lingkungan dan membantu mengurus mengenai Perpajakan usaha desa wisata.
2. Sebagai Lembaga Komersil

Dengan menjadi lembaga Komersil yang membuka ruang lebih luas kepada masyarakat desa untuk meningkatkan penghasilan, BUMDES Singapadu Kaler sudah menjalankan fungsi ini, dapat dilihat dari rencana yang dibuat oleh Kepala Desa dan dibantu oleh BUMDES akan semakin mengembangkan potensi yang ada sehingga jika potensi tersebut dapat berkembang lalu dibuka untuk wisatawan, nantinya membuka lapangan pekerjaan untuk masyarakat desa dan meningkatkan pendapatan masyarakat.

Sehingga analisa yang didapat adalah sebagai berikut:

1.Belum optimalnya BUMDES sebagai:

a.Alat pemerata dan pertumbuhan ekonomi desa

b.Meningkatkan ekonomi dan pendapatan masyarakat

c. Penyerta Modal

2. Sudah Optimal BUMDES sebagai:

a. menciptakan kesejahteraan warga dengan memanfaatkan aset dan potensi yang dimiliki desa

b. Memberikan modal penyertaan dari desa

c. Sebagai lembaga Sosial dan lembaga Komersil

3. Adanya penambahan isi kerjasama terkait jalur khusus ( trekking ) ATV untuk dikelola secara bersama - sama.

Hasil analisis di atas melahirkan beberapa butir poin penting. Untuk Dinas Pariwisata, sebagai monitoring untuk mengawasi kerjasama yang terjalin agar perkembangan di desa Singapadu Kaler dapat terlaksana dengan selaras dan harmonis antara pihak corporate dengan masyarakat lokal. Untuk BUMDES agar lebih mengoptimalkan tugas, tujuan serta fungsinya sesuai ciri - ciri dari BUMDES seperti membantu menyalurkan wisatawan agar terciptanya pemerataan wisatawan yang berdampak pada pendapatan masyarakat, meninjau kembali terkait nominal pembayaran iuran wajib atau pembalikan modal karna masih terdapat perbedaan harga antar unit desa wisata, menghitung ulang mengenai pembagian modal dan membentuk Badan Pengelola untuk menjamin pemerataan operasional yang ada serta mengkoordinir dan mengajak semua unit desa untuk mengelola trekking ATV secara bersama- sama. Selain itu juga 
untuk kerjasama yang terjalin antara pihak Corporate dan BUMDES harus tetap terjaga dan menjalankan Hak \& Kewajiban masing masing agar kerjasasama yang terbentuk dapat terus berjalan dan menghindari wanprestasi. Untuk pihak Desa, agar dapat menambahkan fasilitas seperti petunjuk arah agar wisatawan tidak tersesat menuju lokasi daya tarik wisata. Pada saat ini, lokasi daya tarik wisata di Desa Singapadu Kaler cukup membingungkan terlebih daya tarik wisata yang berlokasi di belakang pemukiman masyarakat.

\section{PENUTUP}

\subsection{Kesimpulan}

Berdasarkan hasil dari pembahasan di atas, maka dapat disimpulkan beberapa hal sebagai berikut :

1. Kondisi eksisting Desa Singapadu Kaler a. Atraksi

Atraksi yang paling unggul dan diminati oleh wisatawan yaitu berupa desa wisata seperti ATV. Dan daya tarik wisata lainnya berupa Flying Fox, Swing ( ayunan ), Sepeda Terbang, Wisata berkuda, Tarian Tradisional, Yoga \& Spa, Tradisi " Nguber Bebek ", Kopi Luwak, Pura \& Sumber Mata air dan Pohon. Selain itu, terdapat beberapa daya tarik wisata tambahan yang baru direncanakan seperti Trekking Persawahan, Subak, Patung, Tempat berjemur di pinggir sungai.

b. Aksesbilitas

Untuk aksesbilitas yang ada di Desa Singapadu Kaler seperti jalan raya sudah bagus tidak ada kerusakan yang parah, untuk mencapai Desa Singapadu Kaler dapat memakai kendaraan pribadi seperti motor atau mobil atau taxi online atau menggunakan bus.

\section{c. Fasilitas}

Fasilitas yang ada di desa Singapadu Kaler sudah cukup memadai seperti restoran, tempat penginapan, lahan parkir yang cukup, pombensin, dan fasilitas kesehatan.

d. Kelembagaan

Kelembagaan yang ada di Desa Singapadu Kaler pun sudah cukup terstruktur dan lengkap seperti Pemerintah, Pengusaha atau Swasta dan masyarakat lokal yang saling bekerjasama dalam mengembangkan desa dan sudah menjalankan tugasnya sesuai hak dan kewajiban. e. Perubahan Desa menjadi Desa Wisata Desa Singpadu Kaler mengalami perubahan semenjak dijadikan Desa Wisata, perubahan tersebut mencakup perubahan yang meliputi kondisi lingkungan yang lebih bersih, dalam ekonomi yaitu menurunnya angka pengangguran dan sosial masyarakat desa seperti adanya kegiatan gotong royong bersama.

2. Kerjasama pihak corporate dengan masyarakat

Dari adanya kerjasama yang dibangun oleh unit desa wisata yaitu pihak corporate dengan masyarakat yang diwakili oleh BUMDES, terdapat hal- hal penting dari kerjasama tersebut seperti:

a. Adanya kesepakatan membentuk Holding Company dengan modal sebesar Rp 500.000.000 dari masing masing unit desa wisata atau 7 kelompok dan juga dari pihak BUMDES.

b. Dalam hal perpajakan, dibantu oleh BUMDES untuk proses pembayaran, namun biaya tetap dikeluarkan atau dibayarkan oleh masingmasing pihak unit desa wisata sesuai perhitungan.

c. Dalam hal Operasional seperti Gaji karyawan sepenuhnya tanggung jawab masingmasing unit desa wisata atau masing - masing pihak corporate.

d. Terdapat iuran wajib yang harus dibayarkan oleh masingmasing unit desa wisata terhadap BUMDES.

e. Semua unit desa wisata mendapatkan perlindungan secara lingkungan dan BUMDES sebagai pihak mediator atau mediasi.

f. Modal yang diberikan BUMDES terhadap unit desa wisata sebesar Rp 70.000.000 dengan sistem pembayaran balik modal sebesar Rp 150.000/hari.

g. Terdapat sanksi jika salah satu pihak melakukan pelanggaran yaitu berupa teguran diawal dan musyawarah jika sangat diperlukan. 


\section{DAFTAR PUSTAKA}

Abdulsyani. 1994. Sosiologi Skematika, Teori, dan Terapan. Jakarta:Bumi Aksara

Bagus, Anak Agung Ari Brahmanta dkk. 2017. Kajian Penyusunan Kriteria - Kriteria Desa Wisata sebagai Instrumen Dasar Pengembangan Desa Wisata. Gianyar

Hariyana, I. K., \& Mahagangga, I. G. A. O. (2015). Persepsi masyarakat terhadap pengembangan Kawasan Goa Peteng Sebagai Daya Tarik Wisata Di Desa Jimbaran Kuta Selatan Kabupaten Badung. Jurnal Destinasi Pariwisata, 3(1), 24-34.

Mahagangga, I. G. A. O., \& NUGROHO, S. (2017). Pemahaman lintas budaya dalam kepariwisataan. Cakra Press bekerja sama dengan Fakultas Pariwisata, Universitas Udayana.

Moleong, Lexy J. 2006. Metodologi penelitian kualitatif. Bandung: PT. Remaja Rosdakarya

Moleong, Lexy J. 2012. Metodologi penelitian kualitatif. Bandung: PT. Remaja Rosdakarya

Pemerintah Indonesia. 2009. Undang- Undang Republik Indonesia Nomor 10 Tahun 2009 tentang Pariwisata.

Pemerintah Indonesia. 2014. Undang - Undang Nomor 6 tahun 2014 tentang Desa.

Redyanto, Fandri Wahyu. Salahudin, S.IP, M.Si, M.P.A dan Dr. Vina Salviana DS, M.Si. 2018. Jurnal Model kerjasama antar Stakeholders dalam pengembangan wisata budaya Dusun Sejo. Diakses tanggal 18 maret 2019

Suryawan, Ida Bagus dan I Gusti Agung Oka Mahagangg. 2017. Penelitian Lapangan 1. Denpasar: Cakra Media dan Fakultas Pariwisata Universitas Udayana

Subekti. 1990. Hukum Perjanjian. Jakarta: PT Intermasa. Cet 12,Hal 1

Suarditya, I Made dan I Nyoman Sunarta. 2017. Jurnal Destinasi Pariwisata Strategi pengembangan Banjar Samu, Singapadu Kaler sebagai desa wisata di Kecamatan Sukawati, Kabupaten Gianyar . Vol. 5, No. 1. Diakses tanggal 20 maret 2019.

W.J.S. Purwadarminta. 1985. Kamus Umum Bahasa Indonesia. Jakarta: Balai Pustaka 